\title{
Stemming the Degeneration: IVD Stem Cells and Stem Cell Regenerative Therapy for Degenerative Disc Disease
}

\author{
Sivakamasundari V and Thomas Lufkin \\ Stem Cell and Developmental Biology, Genome Institute of Singapore, Singapore
}

\begin{abstract}
The intervertebral disc (IVD) is immensely important for the integrity of vertebral column function. The highly specialized IVD functions to confer flexibility and tensile strength to the spine and endures various types of biomechanical force. Degenerative disc disease (DDD) is a prevalent musculoskeletal disorder and is the major cause of low back pain and includes the more severe degenerative lumbar scoliosis, disc herniation and spinal stenosis. DDD is a multifactorial disorder whereby an imbalance of anabolic and catabolic factors, or alterations to cellular composition, or biophysical stimuli and genetic background can all play a role in its genesis. However, our comprehension of IVD formation and theetiology of disc degeneration (DD) are far from being complete, hampering efforts to formulate appropriate therapies to tackle DD. Knowledge of the stem cells and various techniques to manipulate and direct them to particular fates have been promising in adopting a stem-cell based regenerative approach to DD. Moreover, new evidence on the residence of stem/progenitor cells within particular IVD niches has emerged holding promise for future therapeutic applications. Existing issues pertaining to current therapeutic approaches are also covered in this review.
\end{abstract}

Key words: Degenerative disc disease; stem cells; IVD stem cells; niche.

(181 words)

\section{Introduction}

Degenerative disc disease (DDD) is a prevalent musculoskeletal disorder, often associated with low back pain, which can be indicative of severe conditions like disc herniation or prolapse, radiculopathy or spinal stenosis. Low back pain affects about $70 \%$ of the population at some point in their lives (Raj, 2008). It imposes an enormous socio-economic burden on the affected individual and the health care services, with increased medical expenditure and reduced productivity owing to loss of working days. In Sweden, the average annual direct and indirect cost per patient for chronic low back pain in 2002 was US\$2,900 and US\$16,600 respectively (Ekman et al., 2005). In the USA alone, the cost of chronic low back pain exceeds USD $\$ 30$ billion annually, which is in excess of the combined costs of stroke, respiratory infection, diabetes, coronary artery disease and rheumatoid disease (JN, 2006; RZ et al., 2003; Walker, 2000).

DDD is a progressive disorder correlated with age. Mild degeneration has been detected in teens as early as 11- to 16years of age and severe degeneration in $60 \%$ of 70 -year olds (Boos et al., 2002; Miller et al., 1988; Raj, 2008). While debilitating pain in symptomatic DDD compels one to seek appropriate medical attention, a significant proportion of DDD cases are asymptomatic, thus preventing timely intervention (Boden et al., 1990; Boos et al., 1995; Raj, 2008). Such unnoticed DDD worsens with age owing to

Copyright (C) 2013. Sivakamasundari V and Thomas Lufkin. This is an open access article distributed under the Creative Commons Attribution License unported 3.0, which permits unrestricted use, distribution, and reproduction in any medium, provided that original work is properly cited. Contact author: Thomas Lufkin E-mail: lufkin@gis.a-star.edu.sg 
the constant strain applied to the already compromised spine and can eventually lead to permanent disabilities. A myriad of other factors also influence the occurrence of disc degeneration, such as lifestyle, nutrition, body mass index, genetic susceptibility and injury (Alexiou and Voulgaris, 2012; Zhang et al., 2011).

Current clinical therapies for DDD involve symptomatic relief from pain by administering medications or physiotherapy (Chou and Huffman, 2007). Surgeries such as disc arthroplasty, spinal fusion, and disc decompression are employed as a last resort and may involve complications such as adjacent level disease that often warrants further surgical procedures (Levin et al., 2007; Raj, 2008). Such treatment modalities, however, neither arrest the progression of degeneration nor restore the native functional state of the IVD.

Even though numerous factors associated with DDD have been identified, the exact molecular mechanisms of intervertebral disc (IVD) development and pathogenesis of DDD have yet to be elucidated. This dearth in information coupled with the multifaceted nature of the disease thus hampers efforts to formulate appropriate and effective therapies to tackle DDD. Intradiscal injection of growth factors (GFs) has been tested as a means to restore IVD functionality. Expanding knowledge on the stem cells and various techniques to manipulate and direct them to specific fates has promoted a stem cell-based regenerative approach to DDD. In this review, the pathology of DDD, current developments on cell-based therapies, IVD stem/progenitor cells and their niche within the IVD are discussed. Existing issues pertaining to these techniques and factors that need to be considered when undertaking a stem cell-based approach are also covered.

\section{The Healthy Adult IVD}

The vertebral column, with its metameric vertebral bodies and intervertebral discs, is the indispensable mainstay and chief support structure of vertebrates. The fibro- cartilaginous IVD is an integral aspect of the vertebral column connecting adjacent vertebral bodies together. It functions to withstand biomechanical forces, conferring tensile strength, stability and flexibility to the spine. The mature IVD is a highly specialized, multi-component structure, encompassing a central gelatinous nucleus pulposus (NP), encased by a ligamentous annulus fibrosus (AF) and inferiorly and superiorly positioned cartilaginous endplates (EP). The mature IVD is largely avascular and aneural, with vascular ends terminating in the outer $\mathrm{AF}$ (in 10-month old children) or the EP (in adults) and the region within the vertebral bodies adjacent to the EP (Nerlich et al., 2007; Raj, 2008). Similarly, the neural supply (sinovertebral nerves) emerging from the dorsal root ganglion extends only up to the outer annulus (Raj, 2008; Roberts et al., 1995).

In a healthy disc, the necessary nutrition and oxygen are supplied to the AF and NP via diffusion from the blood vessels through the endplates and the lateral boundaries of the AF. The avascular and aneural nature of the disc exposes the contents of the NP to a low oxygen and nutrition environment, which is generally believed to be responsible for its poor regenerative capacity (Raj, 2008; Roberts et al., 1995).

The unique biochemical composition of each of the IVD components impart different biomechanical functions and collectively help the IVD to distribute the load evenly. For instance, the semi-fluidic NP is rich in proteoglycans (e.g. Aggrecan) and Collagen II, whereby the constituent glycosaminoglycans (GAGs) of the proteoglycans are critical in water absorption to maintain the osmotic pressure of the NP. This allows it to resist load and prevents the AF from collapsing inwards. The concentrically arranged lamellae, Collagen I, Collagen II and Elastin fibers of the $\mathrm{AF}$ help to withstand compressive forces and hold the NP in place during compression. The thin endplates composed of hyaline cartilage join the adjacent bony vertebrae to the $\mathrm{AF}$ to provide continuity (Hayes et al., 2011; Raj, 2008). 
The Degenerated IVD

\section{Morphological Hallmarks of Disc Degeneration}

In clinical settings, radiographic and Magnetic Resonance Imaging (MRI)-based imaging are the most commonly used modes of assessment of disc degeneration in patients. Morphological hallmarks of DDD are reduced disc height or collapsed disc space, lack of distinction between boundaries of the annulus and the nucleus pulposus, loss of signal intensity on T2weighted images, lack of homogeneity of the NP and/or disc extension beyond the interspace (DEBIT). Annular ruptures are also detected in degenerated discs, which can explain the extrusion of NP content that can irritate adjacent spinal nerves resulting in pain. Changes to endplate shape, sclerosis, Schmorl's nodes and calcification are also correlated with DDD (Benneker et al., 2005; Pfirrmann et al., 2001).

\section{Biochemical Hallmarks and Pathology of DDD}

DDD ensues with alterations to the biochemical and cellular composition of the IVD. A decrease in large proteoglycans (Aggrecan, Versican), which are essential in retaining water, and a marked increase in Collagen I, and small proteoglycans (Biglycan, Decorin) that play essential roles in matrix organization occur in the NP with ageing and in degeneration. The increase in the relative ratio of small-to-large proteoglycans results in a more fibrous constituency with a reduced ability of NP to retain water (Cs-Szabo et al., 2002; Inkinen et al., 1998; Johnstone and Bayliss, 1995; Lyons et al., 1981). The various factors that contribute to the aberrant biochemical changes of the IVD are discussed in the following sub-sections.

\section{(I) Imbalance of Anabolic and Catabolic Factors}

Deviations from the homeostatic levels of anabolic and catabolic factors are instrumental in the progression of degeneration. Abnormal local production of matrix remodeling enzymes, like matrix metalloproteinases (MMPs), a disintegrin and metalloproteinase with thrombospondin motifs (ADAMTSs) and tissue inhibitor of metalloproteinase (TIMPs) affect the overall matrix turnover in the IVD and result in a net loss of proteoglycans (Liu et al., 1991; Sedowofia et al., 1982; Sternlicht and Werb, 2001). The consequential dehydration of the disc and loss of its structural integrity adversely affect its load-bearing ability. Besides, several inflammatory mediators and cytokines like interleukin-1 (IL-1), interleukin-6 (IL-6), nitric oxide (NO), tumor necrosis factor alpha (TNF-alpha) and prostaglandin $\mathrm{E}_{2}\left(\mathrm{PGE}_{2}\right)$ are known to increase the catabolic factors (MMP3, MMP12, ADAMTS-4) and suppress proteoglycan and collagen production. These pro-inflammatory cytokines may also sensitize the nerves in the IVD, thereby triggering pain in some degenerative conditions (Kang et al., 1997; Le Maitre et al., 2005; Millward-Sadler et al., 2009; Wang et al., 2011).

(II) Cellular Composition of the NP Notochordal Cells and Their Role as “Organizers"

During embryogenesis, the nucleus pulposus is derived through the interaction of the notochord and the sclerotome; the notochord regresses from the sclerotomederived vertebral bodies and expands into the IVD anlagen, thus giving rise to the cells of the NP (Aszodi et al., 1998; Choi et al., 2008; McCann; et al., 2012; Smits and Lefebvre, 2003).

The cells within the mature NP are heterogenous, consisting of two prominent populations - the large vacuolated notochordal cells and small chondrocytelike cells. Lineage tracing experiments by Choi et al (2008) and McCann et al (2012) have shown that the large-vacuolated cells (NP cells) and small chondrocyte-like cells of the mature NP are derived from the notochord (see (Risbud and Shapiro, 2011; Sivakamasundari and Lufkin, 2012) for review on IVD morphogenesis) (Choi et al., 2008; McCann; et al., 2012). 
The changes in the biochemical composition of the IVD is closely linked to changes in the cellular composition in the ageing or degenerate NP (Hunter et al., 2003; Trout et al., 1982; Walmsley, 1953). While the notochordal cells populate the immature NP, they decline in numbers in the mature IVD, which then consists mainly of the chondrocyte-like cells (Walmsley, 1953). Loss of notochordal cells as early as in the teen years has been observed in humans and is postulated to be a key factor in the development of disc degeneration as it has implications in the NP proteoglycan composition (Hunter et al., 2003; Maldonado and Oegema, 1992; Stevens et al., 2000; Trout et al., 1982).

Notably, fundamental differences exist between the characteristics of the notochordal cells and chondrocyte-like cells. Firstly, even though notochordal cells can produce NP matrix proteoglycans, Collagen II and Aggrecan at a rate akin to that of the chondrocyte-like cells of the NP (but in lower levels than that of the NP cells), the chondrocyte-like cells exhibit a faster population doubling time than the notochordal cells (Aguiar et al., 1999; Kim et al., 2009a). Secondly, in vitro imaging of the rabbit notochord cells showed that single notochord cells were able to selfrenew, albeit at a low frequency (1 in 100), but not proliferate unlimitedly. This indicates that the notochord cells are not "stem cells" like but may potentially encompass a "progenitor" subset of cells (Kim et al., 2009a). Furthermore, the notochord cells differentiated into three morphologically different cells: vacuolated cells, polygonal cells and giant cells, significance of which is yet to be elucidated (Kim et al., 2009a). Such imaging studies remain to be shown for the direct conversion of notochordal cells into chondrocyte-like cells. Hence, it is still unclear if the chondrocyte-like cells are a result of the aberrant transformation of the notochordal cells or are derived from one of the three morphologically distinct cells of the NP. Thirdly, the chondrocyte-like cells resemble articular chondrocytes and significant differences exist in the structure of the proteoglycans and the proteoglycan/collagen ratio between the articular cartilage and the NP (Mwale et al., 2004). Additionally, injection of chondrocytes isolated from rabbit ear cartilage into denucleated IVD resulted in the formation of hyaline cartilage instead of a gelatinous NP (Gorensek et al., 2004; Mwale et al., 2004).

Considering that the notochordal cells produce less proteoglycans than the NP cells, proteoglycan production may not be the primary function of the notochordal cells (Aguiar et al., 1999). Rather, they may operate as "organizers" to the surrounding cells in the IVD, a function which probably cannot be matched by the chondrocyte-like cells. It is hypothesized that the early "organizer" functions of the notochord, whereby it serves as a Shh signaling centre to pattern the surrounding paraxial mesoderm and direct them to a sclerotomal fate, may also persist at later stages to maintain the NP homeostasis (Choi et al., 2012; Fan and Tessier-Lavigne, 1994; Hunter et al., 2003; Murtaugh et al., 1999). The adult notochord cells may provide yet unknown cues to the NP cells or other cells of the IVD (eg. stem cells in the IVD stem cell niche), protecting, stimulating or recruiting them to maintain the NP homeostasis. For example, notochordal cells secrete soluble factors that can protect NP cells from matrix degradation and apoptosis by altering matrix remodelling genes (MMP3, ADAMTS-4 and TIMP1) and suppressing activated capases-9/3/7 respectively (Aguiar et al., 1999; Erwin et al., 2011; Nishimura and Mochida, 1998). They can also promote proteoglycan synthesis by the degenerate NP cells when co-cultured or when the NP cells are grown in notochordconditioned medium (Aguiar et al., 1999; Gantenbein-Ritter and Chan, 2012). In addition, some authors have proposed the adult notochord cells to be an "organizer cell" in terms of stimulating the migration of resident stem cells from the IVD niche regions to the NP (Hunter et al., 2003). Through an in vitro cell migration assay, Kim et al (2009) showed the ability of notochord cells to stimulate the migration of EP-derived chondrocytes (Kim et al., $2009 \mathrm{~b})$. Hence, based on these unique properties of the notochord cells, it is 
postulated that the adult notochord cells may be involved in organizing the NP environment by cooperating with the stem cells and other cells of the NP.

Thus, in the ageing or degenerate IVD, the absence of such organizer cells in the IVD could mean an inability to recruit stem/progenitor cells from the surrounding niche regions into the NP for regeneration. The resident NP cells would no longer receive the appropriate "signals" for matrix synthesis to maintain the NP homeostasis. This could explain the poor capacity for regeneration or the lack of maintenance of the IVD despite the presence of the stem/progenitor population in the degenerate IVD (see "The Stem/progenitor Cells and Stem Cell Niche in the IVD" section). One has to ponder whether genetic factors implicated in DDD also play a role in the failure of these cells to maintain the IVD.

\section{(III) Impaired Nutrient Supply}

Importantly, impaired nutrient supply to the IVD cells owing to damage to the endplates (calcification or sclerosis) can negatively alter the microenvironment of the IVD, thus precipitating disc degeneration. The reduced oxygen tension, nutrition and increased acidity of the degenerate IVD diminish the viability of NP cells (increased apoptosis or necrosis) or increases senescence of NP and/or AF cells and adversely affects matrix production (Horner and Urban, 2001; Illien-Junger et al., 2012; Jackson et al., 2011; Li et al., 2012).

\section{(IV) Biophysical Stimuli in Disc Degeneration}

Another well-known factor that can contribute to the biochemical changes seen in DDD is inappropriate biomechanical stress acting on the spine or the lack thereof. A static, unloaded state of the IVD results in degenerative changes such as decreased GAG content, anabolic activity and viability of AF or NP cells, while dynamic loading up-regulated the anabolic genes (Chan et al., 2011; Ching et al., 2004; MacLean et al., 2003; Paul et al., 2012;
Wilke et al., 1999). At the same time, the favorable effects of dynamic loading is dependent on its magnitude, frequency and duration; stepping beyond a certain range of all these parameters induced degenerative changes such as reduced proteoglycan synthesis and increased catabolic remodeling and apoptosis of NP or AF cells (Maclean et al., 2004, 2005; Walsh and Lotz, 2004; Wuertz et al., 2009) (see (Chan et al., 2011) for a detailed review). Indeed, cells of the NP and AF exhibit different viscoelastic properties in vitro, which are postulated to result in different metabolic responses (proteoglycan and collagen synthesis) to mechanical loading (Guilak et al., 1999). Thus, diurnal mechanical loading activities may act as biophysical signal in healthy IVD cells, by yet unknown mechanisms, thereby stimulating them to maintain appropriate matrix turnover.

\section{(V) Genetic Influence}

Like many other diseases, the genetic background of the individual also plays a role in disc degeneration. DDD is polygenic as mutations in a multitude of genes encoding structural proteins, interleukins, apoptosis regulators or MMPs have been associated with risk for DDD and/or disc dehydration and disc height narrowing. These genes include ACAN, COL9A1, COL9A2, COL9A3, COL1A1, COL11A1, IL1A, IL18RAP, IL18R1, IL-10, CASP9, BCL-2 and MMP9 (Cong et al., 2010; Kalichman and Hunter, 2008; Lin et al., 2011; Shang et al., 2012; Solovieva et al., 2007; Sun et al., 2011; Sun et al., 2009; Videman et al., 2009). A recent population based study also provided evidence for a heritable predisposition to developing symptomatic lumbar disc disease (Patel et al., 2011). How such genetic predisposition and association with degenerative changes will affect therapeutic outcomes is not known. Then again, such information would be useful for pre-emptive measures against developing DDD. Studies addressing this issue may, in the future, help to steer therapies towards a more personalized approach. 


\section{Resolving DDD}

The knowledge of the pathology of DDD, namely the alterations to the cellular composition and biochemical changes of the NP, can be utilized for its resolution. Employing the most appropriate therapeutic strategy based on the level of degeneration is imperative to derive the most favorable outcome for patients. An ideal therapy would be one that is minimally invasive, not requiring hospitalization and improved pain relief as well as restoring disc function. In mild degenerative conditions, a conservative approach is taken mainly to reduce pain, which includes physiotherapy (biomechanical stimuli), and administration of medications such as NSAIDs, acetaminophen, tricyclic antidepressants (for chronic pain) and muscle relaxants (Chou and Huffman, 2007). At intermediate levels of disc degeneration, protein injections, cell therapy or gene therapy approaches could be adopted. With severe cases of degeneration, surgeries such as total disc replacement and spinal fusion may be the only viable options (Zhang et al., 2011).

The premise of protein injections, or gene therapy relies on the fact that remaining healthy endogenous cells can be stimulated to proliferate and/or re-establish the matrix homeostasis, thereby restoring the NP and/or AF tissues. Numerous GFs such as BMP7 (OP-1) (Imai et al., 2007; Masuda et al., 2003; Miyamoto et al., 2006), BMP14 (GDF-5) (Li et al., 2004; Walsh et al., 2004), TGF-B (Gruber et al., 1997; Hayes and Ralphs, 2011; Thompson et al., 1991), IGF1 (Hayes and Ralphs, 2011; Osada et al., 1996), bFGF (Pratsinis et al., 2012), PDGF (Pratsinis et al., 2012), BMP12 (Gilbertson et al., 2008), BMP13 (GDF6) (Wei et al., 2009b) and BMP2 (Gilbertson et al., 2008; Tim Yoon et al., 2003)) have been investigated for this purpose in various in vitro or in vivo conditions (for detailed reviews see (Masuda, 2008; O'Halloran and Pandit, 2007)). They produced promising results such as elevating the proteoglycan content of the NP and AF, and/or stimulating the proliferation of the endogenous cells, thus assisting in restoring their biomechanical properties.
In fact, recombinant GDF5 (rhGDF5) is currently under human Phase I/II clinical trials for the treatment of early stage lumbar disc degeneration (Advanced Technologies and Regenerative Medicine, 2012; Zhang et al., 2011). Noteworthy, some BMPs possess the risk of causing pathological bone formation within the IVD (Zara et al., 2011). BMP13 is particularly promising owing to its ability to inhibit osteogenic differentiation of human bone marrow derived MSCs (BM-MSCs) but promote a chondrogenic fate (Shen et al., 2009a). Whether it would serve as a suitable therapeutic agent for DDD therapy has to be ascertained in the future.

The main advantage of intradiscal protein injection is that it does not involve complicated surgical procedures. However, the drawbacks are that the therapeutic effects are transient and at more advanced levels of disc degeneration, the endogenous cells may no longer be responsive to such stimuli or there may be insufficient number of functional cells in the IVD to begin with (Le Visage et al., 2006; Masuda, 2008).

Nonetheless, cell therapy could circumvent the problem of short-lived effect of protein injections. Based on numerous in vitro and in vivo studies on rat, rabbit, canine, porcine, ovine, bovine and human, IVD cells, including notochordal cells and NP cells are potentially the ideal choice for transplantation procedures (for a detailed review on cell types, culture conditions and scaffolds used for IVD repair see (O'Halloran and Pandit, 2007)). Their ability to increase the proteoglycan content, viability upon transplantation and established protocols to expand them in vitro are advantageous for cell therapy (Erwin et al., 2011; Ghosh et al., 2012; Iwashina et al., 2006; Nishimura and Mochida, 1998; Nomura et al., 2001; Okuma et al., 2000). For instance, implantation of autologous NP cells or entire NP, retarded disc degeneration (Nishimura and Mochida, 1998; Nomura et al., 2001; Okuma et al., 2000). Also, injection of immortalized human NP cells into degenerate rabbit disc preserved the matrix of NP and decelerated its degradation (2003; Iwashina et al., 2006). 
On the contrary, chondrocytes are unsuitable since their injection into the rabbit IVD resulted in the formation of hyaline cartilage instead of a gelatinous NP (Gorensek et al., 2004). Thus, introduction of autologous notochordal or NP cells into the affected IVD could replenish and thereby restore the IVD to its healthy state or at the least, reduce the rate of degeneration.

It is noteworthy though that cells harvested from a degenerated IVD may not be suitable as they exhibit senescence with an altered molecular phenotype and distinct pathology (Gruber et al., 2009; Roberts et al., 2006). Similarly, autologous cells harvested from patients who are genetically susceptible to DDD may prove inferior for cell therapy since they are already pre-disposed to degeneration (Gruber et al., 2006; Richardson et al., 2007). In addition, obtaining healthy notochord cells is not a feasible option owing to the absence of such cells in adults.

Gene therapy is one avenue to enhance the biological activity of the IVD cells. Transfection of degenerate human NP cells with anti-catabolic TIMP-1 resulted in increased proteoglycan production in vitro (Wallach et al., 2003). Likewise, NP cells transfected in vitro with CTGF and TIMP-1 genes (using viral vectors) in rhesus monkey and rabbit animal models showed increased proteoglycan and Collagen II production (Liu et al., 2010; Liu et al., 2011b). In the latter study, transplantation of the modified cells back into the rabbit IVD resulted in a reversal of disc degeneration (Liu et al., 2011b). Therefore, the ability of degenerate NP cells to produce the required matrix proteins could be revived through genetic modification, after which the transgenic cells can be transplanted into the degenerate IVD to restore its function.

The caveat with this approach is that viral vectors are often used for gene transfer, so their safety and effectiveness need to be thoroughly evaluated before being employed in human trials. More importantly, harvesting adult NP or AF cells from prospective healthy discs of the patients is also counterproductive as it could result in increased morbidity or further damage to the IVD. Therefore, stem cells, which possess multi-lineage differentiation potential, could be utilized if they could be successfully directed to a NP or AF cell fate before transplantation.

\section{Stem Cell Therapy}

Stem cells are a boon to medical science and hold great promise for regenerative therapy. They are unique in that they are pluripotent (e.g. embryonic stem cells, ESCs) or multipotent (e.g. mesenchymal stem cells, MSCs), possessing the ability to self-renew as well as differentiate into specific cell lineages. ESCs are derived from inner cell mass of blastocysts, and have an advantage over MSCs as they can give rise to cells from all three germ layers (endoderm, mesoderm and ectoderm) and exhibit extensive proliferation ability in vitro. In spite of this, their usage in clinical settings is hindered by a number of other factors such as: difficulties in acquisition owing to ethical concerns, immune rejection after allogeneic transplantation, risk of disease transmission and the possibility of teratoma formation (Satija et al., 2007).

On the contrary, MSCs overcome several of these hurdles for clinical application. Firstly, even though they exhibit limited capacity to proliferate in vitro, they can be isolated from multiple sources such as, adipose tissue, blood, synovial membrane, deciduous teeth, dermis, muscle or periosteum (Friedenstein et al., 1976; Pittenger et al., 1999; Richardson et al., 2010; Satija et al., 2007; Shi and Gronthos, 2003). Secondly, they can be expanded in vitro and directed to a selective set of adult tissue lineages like chondrogenic, osteogenic, adipogenic, myogenic, tendon or neurogenic fates in appropriate culture conditions (Dezawa, 2008; Lin et al., 2008; Pittenger et al., 1999; Wang et al., 2005). Thirdly, they express chemotactic receptors and MMPs for matrix remodeling, which confer them with the ability to home or "engraft" to sites of injury in response to cytokines; a property that would serve well for regeneration of degenerated tissues (Ji et al., 2004; Mauney et al., 2010; Ponte et al., 2007; Ries et al., 
2007). A recent study by Illien-Junger et al (2012) showed that BM-MSCs had a greater ability to home to the NP/AF of the degenerated discs compared to healthy discs in a bovine organ culture model (Illien-Junger et al., 2012). Fourthly, they are hypoimmunogenic owing to their lack of expression of HLA class-II molecules and the ability to inhibit T-cell proliferation and maturation (Chanda et al., 2010; Deschaseaux et al., 2003; Jarvinen et al., 2008). This property might be advantageous in situations requiring allogeneic transplantation of MSCs. A caveat, though, is that ex vivo cultured murine MSCs were shown to develop osteosarcomas (Tolar et al., 2007). Then again, another study showed that prolonged culturing of human BM-MSCs did not result in malignant transformation of the cells, but majority of them attained senescence by passage 25 (Bernardo et al., 2007). Thus, it is imperative that sufficient precautionary measures be taken when preforming stem cell transplantations in humans.

\section{MSCs for DDD Therapy}

In stem cell therapy, some critical questions need to be addressed namely: can the cells be differentiated to the correct phenotype; are they viable on the longterm in the degenerate environment; can they restore the degenerated disc at the biochemical (proteoglycan, collagen and water content) and structural (AF tissue repair, disc height restoration) level; can sufficient numbers of stem cells be procured in a feasible manner; and most importantly, would these cells be safe for transplantation?

Several investigators have studied the ability of MSCs to promote matrix synthesis and attempted to differentiate them to NP or AF cell fates either through co-culture experiments, using growth factor(s) supplemented media or by directly injecting them into the IVD.

\section{(I) MSC Differentiation towards NP Cell Type}

In vitro experiments on rat, rabbit and human cells showed that proteoglycan content and cell proliferation improved when NP cells were co-cultured with MSCs with direct cell-to-cell contact (Richardson et al., 2006; Watanabe et al., 2010; Wei et al., 2009a; Yamamoto et al., 2004). Bidirectional exchange of membrane components occur between the MSCs and NP cells which was proposed by the authors as a key mode of communication between the two cell types in the direct coculture conditions (Strassburg et al., 2012). In addition, Richardson et al (2006) showed that a $3: 1$ ratio of NP: MSC is optimal for the differentiation of human BM-MSCs into "NP-like" cells (Richardson et al., 2006).

Likewise, MSCs cultured in vitro in 3dimensional, hypoxic culture conditions, with TGF-B1 supplemented media exhibited a NP-like phenotype (Risbud et al., 2004; Steck et al., 2005). Other growth factors, such as BMPs $(2 / 4 / 6 / 7 / 9)$ in combination with TGF-Bs $(1 / 2 / 3)$, have also been investigated for their ability to differentiate bone-marrow or adipose tissue derived MSCs towards a chondrogenic phenotype for use in IVD or cartilage repair (Puetzer et al., 2010). Notably, the best combination of factors required for inducing chondrogenic differentiation differs for BM-MSCs and adipose tissue derived stromal cells (ADSCs). For example, in BM-MSCs, both BMP2 and TGF-B3 synergistically induced chondrogenic differentiation when cultured in high-density or in alginate beads (Schmitt et al., 2003; Shen et al., 2009b). Whereas for ADSCs, a combination of TGF-B2 and BMP7 proved most effective in promoting a chondrogenic fate, compared to a combination of other BMPs (2/6/7) with TGF-B2 (Kim and Im, 2009) (readers may refer to the review by (Puetzer et al., 2010) on growth factors for effective chondrogenic differentiation of the MSCs).

It has to be noted, however, that such MSCs differentiated towards the chondrogenic fates may not necessarily be ideal for IVD repair. As mentioned before, injection of chondrocytes into the NP resulted in the formation of hyaline cartilage instead of a gelatinous matrix (Gorensek et al., 2004). 
Hence, directing the MSCs towards specific $\mathrm{NP}$ or AF fates is crucial to ensure effective disc repair. Nevertheless, these studies serve as a starting point to optimize the culture conditions for efficiently attaining NP or AF cell fates from the MSCs.

\section{(II) MSC Differentiation towards AF Cell Type}

Unlike the NP cells, far fewer attempts have been made to differentiate MSCs towards an AF cell type. In the adult IVDs, the AF consists of fibroblastic cells arranged radially around the NP. During embryonic development, the inner $\mathrm{AF}$ is cartilaginous while the outer $\mathrm{AF}$ is fibrous. The inner $\mathrm{AF}$ is rich in Collagen II while the outer AF has a greater proportion of Collagen I. During post-natal development, the $\mathrm{AF}$ attains a fibrocartilaginous phenotype with increased GAG and Collagen II production, and the distinction between the inner $\mathrm{AF}$ and outer AF becomes less obvious (Hayes et al., 2011). Recently, See et al (2012) have utilized a tissue engineering approach to regenerate AF-like cells. They simulated an IVD-assembly using sheets of BM-MSCs transplanted onto silk scaffolds, which was then wrapped around cylindrical silicone NP substitute. After 4 weeks of culturing in static environment, the BM-MSCs resembled an inner $\mathrm{AF}$ more than outer $\mathrm{AF}$ based on the higher proportion of Collagen II production compared to Collagen I (See et al., 2012). Also, application of axial compression forces to the IVD-assembly promoted a greater production of Collagen II compared to static conditions, which still resembled inner AF (See et al., 2011).

Regeneration of AF-like tissue that more closely resembles the native fibroblastic $\mathrm{AF}$ would be valuable for rectifying or sealing annular tears. A key limitation pertaining to these studies is the lack of reliable phenotypic markers specific for AF cell type.

Notably, in a number of these studies, the mere expression of a limited number of markers, mainly Collagen II, Aggrecan and Sox9, was deemed to represent the NP-like phenotype (Richardson et al., 2006; Steck et al., 2005; Wei et al., 2009a). However, both NP and articular chondrocytes cells express key extracellular matrix (ECM) genes and transcription factors like SOX9, ACAN and COL2A1 at equally high levels, so they cannot be used as reliable markers to distinguish between both the cell types (Minogue et al., 2010). These authors resorted to using a limited number of markers for assessment because more specific human NP cell markers were not identified prior to the molecular profiling study by Minogue et al in 2010 (Minogue et al., 2010). Nevertheless, in the future, the true NP phenotype of MSCs after differentiation could be assessed more rigorously using multiple, species-specific markers (e.g. PAX1, FOXF1, OVOS2, CA12, HIF-a, GLUT-1 and MMP2) (Minogue et al., 2010; Power et al., 2011; Rajpurohit et al., 2002; Risbud et al., 2006).

Moreover, these studies failed to assess the proteoglycan-to-collagen ratio (GAG:hydroxyproline ratio) of the secreted matrix, which is an alternative way to affirm that the matrix resembles that of a NP rather than hyaline cartilage. The hyaline cartilage (produced by chondrocytes) is composed of proteoglycan:collagen at a ratio of $2: 1$ whereas the NP matrix (from healthy IVD) encompasses a different ratio of 27:1 which permits greater capacity for water retention, thus giving the NP its gelatinous consistency (Mwale et al., 2004). Besides, the morphology of the differentiated MSCs ought to be examined to confirm that the differentiated cells are of a NP phenotype.

\section{(III) Injection of MSCs}

In a clinical setting, expansion of autologous MSCs in vitro is time consuming and extreme care is needed to avoid contamination. Hence, it was investigated if the IVD microenvironment would promote the differentiation of MSCs towards a "NP phenotype" in vivo and restore the proteoglycan content of the IVD. Injection of MSCs directly into the IVD (with or without carrier/scaffold) showed promising results, whereby the injected cells were viable, differentiated into a "NPlike phenotype", promoted matrix synthesis and restored disc height in rat, 
rabbit and canine models as well as in xenogeneic transplant of human MSCs into a porcine model (Crevensten et al., 2004; Henriksson et al., 2009b; Hiyama et al., 2008; Hohaus et al., 2008; Le Maitre et al., 2009; Sakai et al., 2006; Sakai et al., 2005). Additionally, MSCs demonstrated comparable ability for GAG and Collagen II production as NP cells in the rabbit model (Feng et al., 2011). Thus, MSCs clearly appear to be suitable for regeneration of NP tissue.

Some of the main concerns that ought not to be overlooked in MSC therapy are the survival of the injected cells, rejection by host immune system and potential adverse effects of the carriers used for transplantation.

Viability of the transplanted cells is often a point of criticism in cell therapy, considering the hostile environment (hypoxia, low-nutrient levels, presence of inflammatory cytokines and matrix degrading enzymes) of the degenerate IVD (Sakai, 2008). Apparently, survival of the transplanted cells is imperative to ensure disc repair. In most of the studies, the transplanted cells were shown to be viable from 1 to 6 months (i.e. for the maximum investigation period that was carried out in each study) (Hohaus et al., 2008; Iwashina et al., 2006; Le Maitre et al., 2009; Sakai et al., 2003). Furthermore, in xenotransplantation of human MSCs into porcine discs or murine ESC-derived chondroprogenitors into rabbit discs, the injected cells survived up to 6 months and 2 months respectively, without immunosuppressant administration (Henriksson et al., 2009b; Sheikh et al., 2009). It is believed that the avascular nature of the NP might allow it to be immunoprivileged, thus reducing the risk of any graft-versus-host reaction upon implantation of allogenic or xenogeneic cells (Raj, 2008; Sheikh et al., 2009). Nonetheless, appropriate precautionary measures must be taken when it comes to allogenic cell transplantation in humans.

Carriers such as Atelocollagen $\AA$, hyaluronic acid, and injectable hydrogels are commonly used to retain the transplanted cells at the site of injection, mimic the IVD environment to facilitate the survival of the transplanted cells and/or promote matrix production (Collin et al., 2011; Henriksson et al., 2012a). Atelocollagen ${ }^{\circledR}$ is known to enable the proliferation, matrix synthesis and assist in the differentiation of the MSCs (Sakai et al., 2003; Uchio et al., 2000). Hyaluronic acids, on the other hand, do not sufficiently result in disc rehydration on their own, but show favorable disc repair when used in conjunction with stem cells (Hohaus et al., 2008). Moreover, a recent study by Henriksson et al (2012) showed that hyaluronan-based hydrogel caused hyperproliferation of transplanted cells in vivo and resulted in bone formation in the IVD, indicating its unsuitability for use in cell transplantation (Crevensten et al., 2004; Henriksson et al., 2012a) (for discussion on various hydrogels used for IVD repair, see a recent review by (Chan and Gantenbein-Ritter, 2012); see review by (O'Halloran and Pandit, 2007) for more information on cell types and scaffolds used in cell therapy). Therefore, a thorough in vivo investigation for each type of carrier is vital before they are used in human cell therapy.

\section{(IV) Human Trials}

Encouraging results from the numerous in vivo cell transplantation studies prompted a pilot Phase I study by Orozco et al (2011) in 10 patients suffering from chronic low back pain and lumbar disc degeneration. Autologous BM-MSCs expanded in vitro under Good Manufacturing Practice (GMP) conditions were injected (spinal needles) into the NP of affected IVDs. This procedure did not involve any major surgical operation and only required local anesthesia and mild sedation. In a 1-year followup, 9 out of 10 patients showed improved pain relief and water content of the discs, but no improvement in disc height was observed. Whether disc height improvement would be observed over time is yet to be seen. The authors relegated the analgesic effects to potential induction of anti-inflammatory cytokines by the MSCs (Chanda et al., 2010; Orozco et al., 2011). 
A similar FDA-approved trial has begun at the Washington Center for Pain Management in the USA in 2012, which aims to conduct a study on 100 patients for a period of 3 years. The researchers proposed to use bone marrow derived mesenchymal precursor cells in conjunction with a hyaluronic acid carrier (Wash, 2012 ). While such short-term outcomes from these human clinical trials appear promising, long-term improvements and safety measurements are essential.

\section{The Stem/Progenitor Cells and Stem Cell Niche in the IVD}

\section{(I) IVD Stem/Progenitor Cells}

In parallel, researchers have sought after IVD progenitor cells or a stem cell niche in the IVD. Stem cell niches are specific anatomical regions in which stem cells reside in a quiescent state ('slow cycling cells') until activated by specific signals such as those arising from injury, upon which they can produce daughter cells which then differentiate into the required cell type to replace or repair the damaged tissue (Henriksson and Brisby, 2012).

Lately, numerous studies have emerged that have successfully isolated cells with stem cell markers from the IVD. Risbud et al (2007) first identified a proliferating population of skeletal progenitors to reside within the NP and AF of moderately degenerated human IVDs. These progenitor cells expressed general stem cell markers (CD90, CD105, CD166 and CD133/1) and osteogenic precursor markers (CD63 and CD49a). They were also capable of differentiation to osteogenic, chondrogenic and adipogenic lineages in vitro (Risbud et al., 2007). Blanco et al (2010) reproduced those results by isolating cells with stem cell/progenitor markers from the degenerate human NP, but the cells isolated in their study could not be differentiated to the adipogenic lineage (Blanco et al., 2010). Likewise, Liu LT et al (2011) isolated cells expressing the stem cell/progenitor markers (CD90, CD105, CD166, CD133/1 and STR0-1) from the degenerate human cartilage EP. These cells also highly resembled BM-MSCs in terms of immunophenotype, gene expression profile, proliferation capacity and differentiation to all three lineages (Liu et al., 2011a). More recently, Erwin et al (2011) isolated stem/progenitor cells from the canine NP, which they named as nucleus pulposus progenitor cells (NPPCs). Their isolation criteria, however, was based on a different set of stem cell markers, namely Sox2, Oct3/4, Nanog, CD133, Nestin and NCAM. These cells were capable of differentiation into chondrogenic, adipogenic and neural lineages in vitro, and to the neural lineage in vivo (Erwin et al., 2011).

The above-mentioned results from different groups clearly indicate the presence of stem/progenitor cells in the IVD. The lack of standardization on the repertoire of markers used to isolate these cells from the NP/AF/EP, the degree of degeneration in the discs that were used for cell isolation and the experimental techniques employed could explain the discrepancies in terms of the differentiation potential exhibited by the isolated cells.

\section{(II) Stem Cell Niche in the IVD}

Using a repertoire of stem cell/progenitor markers (STRO-1, C-KIT, NOTCH1, DLL4 and $J A G 1$ ), Henriksson $\mathrm{H}$ et al (2009) identified stem cell niches in the AF border to ligament zone and the perichondrium of rabbit, pig and human IVD samples. They proposed that these stem/progenitor cells are recruited to the $\mathrm{NP}$ or $\mathrm{AF}$, and in combination with MSCs from the bone marrow niche (in the EP) they execute their regenerative functions in a healthy IVD (Henriksson et al., 2009a). In support of this, they recently showed that the slowcycling' cells in the rabbit IVD express migration and epithelial-mesenchymal transition (EMT) markers like SNAI1, SLUG and ITGB1 in the niche region in the early time-points, along the migratory route and the outer $\mathrm{AF}$ at later time points (Henriksson et al., 2012b). Still, more robust experimental evidence is required to definitively prove the migration of 
stem/progenitor cells from the niche regions. In vivo cell tracking or in vitro migration assays of the isolated stem/progenitor cell population from the niche regions could be performed.

\section{Future Directions}

The etiology of degenerative disc disease (DDD) is complex and has yet to be fully understood. Numerous therapies have been developed but administering the right type of therapy based on the level of degeneration is critical. In moderate degrees of degeneration, autologous MSC transplantation appears promising in terms of restoring the NP water content and alleviating the pain associated with disc degeneration. Long-term studies on patients are still pending before the safety and efficacy of this approach can be fully determined.

Also, it is still unclear how pre-disposition to DDD or the presence of calcified or sclerotic EP, may affect the outcome of autologous cell transplantation. Use of protein injections (GFs, anti-catabolic factors) in conjunction with stem cell therapy may help to enhance the microenvironment of the IVD to be more conducive for the initial phase of MSC survival and differentiation in vivo.

Furthermore, alternative sources of MSCs such as adipose tissue derived stromal cells (ADSCs) are gaining attention for DDD therapy owing to their ease of acquisition and in greater numbers, through simple outpatient liposuction procedures. Whether they possess equal capacity to restore the IVD matrix is a question that remains to be addressed. More importantly, the identification of stem/ progenitor cells in the IVD is an exciting finding as they are similar to BM-MSCs, implicating the ability to harness the capabilities of their "stemness" to achieve the desired NP fate in vivo. The possibility of stimulating the resident stem/progenitor cells holds tremendous promise for the future.

\section{References}

Advanced Technologies and Regenerative Medicine, L. A. (2012). "Intradiscal rhGDF-
5 Phase I/II Clinical Trial,"(ClinicalTrials.Gov, A service of the $\mathrm{NIH}$.

Aguiar, D. J., Johnson, S. L. \& Oegema, T. R. (1999). "Notochordal Cells Interact with Nucleus Pulposus Cells: Regulation of Proteoglycan Synthesis," Exp Cell Res 246, 129-137.

Alexiou, G. A. \& Voulgaris, S. (2012). "The Influence of Body Mass Index on Lumbar Disc Degeneration," Arthritis Rheum.

Aszodi, A., Chan, D., Hunziker, E., Bateman, J. F. \& Fassler, R. (1998). "Collagen II is Essential for the Removal of the Notochord and the Formation of Intervertebral Discs," J Cell Biol 143, 1399-1412.

ATRM, (2003). "Abstracts of the 18th North American Spine Society 18th Annual Meeting. San Diego, California, USA, October 21-25, 2003," Spine J 3, 67S-180S.

Benneker, L. M., Heini, P. F., Anderson, S. E., Alini, M. \& Ito, K. (2005). "Correlation of Radiographic and MRI Parameters to Morphological and Biochemical Assessment of Intervertebral Disc Degeneration," Eur Spine J 14, 27-35.

Bernardo, M. E., Zaffaroni, N., Novara, F., Cometa, A. M., Avanzini, M. A., Moretta, A., Montagna, D., Maccario, R., Villa, R., Daidone, M. G. et al. (2007). "Human Bone Marrow Derived Mesenchymal Stem Cells do not Undergo Transformation after LongTerm in Vitro Culture and do not Exhibit Telomere Maintenance Mechanisms," Cancer Res 67, 9142-9149.

Blanco, J. F., Graciani, I. F., Sanchez-Guijo, F. M., Muntion, S., Hernandez-Campo, P., Santamaria, C., Carrancio, S., Barbado, M. V., Cruz, G., Gutierrez-Cosio, S. et al. (2010). "Isolation and Characterization of Mesenchymal Stromal Cells from Human Degenerated Nucleus Pulposus: Comparison with Bone Marrow Mesenchymal Stromal Cells from the Same Subjects," Spine (Phila Pa 1976) 35, 22592265. 
Boden, S. D., Davis, D. O., Dina, T. S., Patronas, N. J. \& Wiesel, S. W. (1990). "Abnormal Magnetic-Resonance Scans of the Lumbar Spine in Asymptomatic Subjects. A Prospective Investigation," The Journal of bone and joint surgery American volume 72 , 403-408.

Boos, N., Rieder, R., Schade, V., Spratt, K. F., Semmer, N. \& Aebi, M. (1995). 1995 Volvo Award in clinical sciences. "The Diagnostic Accuracy of Magnetic Resonance Imaging, Work Perception, and Psychosocial Factors in Identifying Symptomatic Disc Herniations," Spine (Phila Pa 1976) 20, 2613-2625.

Boos, N., Weissbach, S., Rohrbach, H., Weiler, C., Spratt, K. F. \& Nerlich, A. G. (2002). "Classification of Age-Related Changes in Lumbar Intervertebral Discs: 2002 Volvo Award in Basic Science," Spine (Phila Pa 1976) 27, 2631-2644.

Chanda, D., Kumar, S. \& Ponnazhagan, S. (2010). "Therapeutic Potential of Adult Bone Marrow-Derived Mesenchymal Stem Cells in Diseases of the Skeleton," J Cell Biochem 111, 249-257.

Chan, S. C. W., Ferguson, S. J. \& GantenbeinRitter, B. (2011). "The Effects of Dynamic Loading on the Intervertebral Disc," Eur Spine J 20, 1796-1812.

Chan, S. C. W. \& Gantenbein-Ritter, B. (2012). "Intervertebral Disc Regeneration or Repair with Biomaterials and Stem Cell Therapy--Feasible or Fiction?," Swiss Med Wkly 142, w13598.

Ching, C. T. S., Chow, D. H. K., Yao, F. Y. D. \& Holmes, A. D. (2004). "Changes in Nuclear Composition Following Cyclic Compression of the Intervertebral Disc in an in Vivo RatTail Model," Med Eng Phys 26, 587-594.

Choi, K. S., Cohn, M. J. \& Harfe, B. D. (2008). "Identification of Nucleus Pulposus Precursor Cells and Notochordal Remnants in the Mouse: Implications for Disk Degeneration and Chordoma Formation," Dev Dyn 237, 3953-3958.
Choi, K. S., Lee, C. \& Harfe, B. D. (2012). "Sonic Hedgehog in the Notochord is Sufficient for Patterning of the Intervertebral Discs," Mech Dev 129, 255262.

Chou, R. \& Huffman, L. H. (2007). "Medications for Acute and Chronic Low Back Pain: A Review of the Evidence for an American Pain Society/American College of Physicians Clinical Practice Guideline," Ann Intern Med 147, 505-514.

Collin, E. C., Grad, S., Zeugolis, D. I., Vinatier, C. S., Clouet, J. R., Guicheux, J. J., Weiss, P., Alini, M. \& Pandit, A. S. (2011). "An Injectable Vehicle for Nucleus Pulposus Cell-Based Therapy," Biomaterials 32, 2862-2870.

Cong, L., Pang, H., Xuan, D. \& Tu, G. J. (2010). "Association between the Expression of Aggrecan and the Distribution of Aggrecan Gene Variable Number of Tandem Repeats with Symptomatic Lumbar Disc Herniation in Chinese Han of Northern China," Spine (Phila Pa 1976) 35, 1371-1376.

Crevensten, G., Walsh, A. J., Ananthakrishnan, D., Page, P., Wahba, G. M., Lotz, J. C. \& Berven, S. (2004). "Intervertebral Disc Cell Therapy for Regeneration: Mesenchymal Stem Cell Implantation in Rat Intervertebral Discs," Ann Biomed Eng 32, 430-434.

Cs-Szabo, G., Juan, D. R.- S., Turumella, V., Masuda, K., Thonar, E. J.- M. A. \& An, H. S. (2002). "Changes in mRNA and Protein Levels of Proteoglycans of the Anulus Fibrosus and Nucleus Pulposus during Intervertebral Disc Degeneration," Spine (Phila Pa 1976) 27, 2212-2219.

Deschaseaux, F., Gindraux, F., Saadi, R., Obert, L., Chalmers, D. \& Herve, P. (2003). "Direct Selection of Human Bone Marrow Mesenchymal Stem Cells Using an AntiCD49a Antibody Reveals Their CD45med, Low Phenotype," Br J Haematol 122, 506517.

Dezawa, M. (2008). "Systematic Neuronal and Muscle Induction Systems in Bone Marrow Stromal Cells: The Potential for 
Tissue Reconstruction in Neurodegenerative and Muscle Degenerative Diseases," Med Mol Morphol 41, 14-19.

Ekman, M., Jonhagen, S., Hunsche, E. \& Jonsson, L. (2005). "Burden of Illness of Chronic Low Back Pain in Sweden: A CrossSectional, Retrospective Study in Primary Care Setting," Spine (Phila Pa 1976) 30, 1777-1785.

Erwin, W. M., Islam, D., Inman, R. D., Fehlings, M. G. \& Tsui, F. W. (2011). "Notochordal Cells Protect Nucleus Pulposus Cells from Degradation and Apoptosis: Implications for the Mechanisms of Intervertebral Disc Degeneration," Arthritis Res Ther 13, R215.

Fan, C. M. \& Tessier-Lavigne, M. (1994). "Patterning of Mammalian Somites by Surface Ectoderm and Notochord: Evidence for Sclerotome Induction by a Hedgehog Homolog," Cell 79, 1175-1186.

Feng, G., Zhao, X., Liu, H., Zhang, H., Chen, X., Shi, R., Liu, X., Zhang, W. \& Wang, B. (2011). "Transplantation of Mesenchymal Stem Cells and Nucleus Pulposus Cells in a Degenerative Disc Model in Rabbits: A Comparison of 2 Cell Types as Potential Candidates for Disc Regeneration," J Neurosurg Spine 14, 322-329.

Friedenstein, A. J., Gorskaja, J. F. \& Kulagina, N. N. (1976). "Fibroblast Precursors in Normal and Irradiated Mouse Hematopoietic Organs," Exp Hematol 4, 267-274.

Gantenbein-Ritter, B. \& Chan, S. C. W. (2012). "The Evolutionary Importance of Cell Ratio between Notochordal and Nucleus Pulposus Cells: An Experimental 3D co-Culture Study," Eur Spine J 21 Suppl 6, S819-825.

Ghosh, P., Moore, R., Vernon-Roberts, B., Goldschlager, T., Pascoe, D., Zannettino, A., Gronthos, S. \& Itescu, S. (2012). "Immunoselected STRO-3+ Mesenchymal Precursor Cells and Restoration of the Extracellular Matrix of Degenerate
Intervertebral Discs," J Neurosurg Spine 16, 479-488.

Gilbertson, L., Ahn, S. H., Teng, P. N., Studer, R. K., Niyibizi, C. \& Kang, J. D. (2008). "The Effects of Recombinant Human Bone Morphogenetic Protein-2, Recombinant Human Bone Morphogenetic Protein-12, and Adenoviral Bone Morphogenetic Protein-12 on Matrix Synthesis in Human Annulus Fibrosis and Nucleus Pulposus Cells," Spine J 8, 449-456.

Goetzel, R. Z., Hawkins, K., Ozminkowski, R. J. \& Wang, S. (2003). "The Health and Productivity Cost Burden of the "Top 10" Physical and Mental Conditions Affecting Six Large U.S. Employers in 1999," J Occup Environ Med 45, 5-14.

Gorensek, M., Jaksimovic, C., KregarVelikonja, N., Knezevic, M., Jeras, M., Pavlovcic, V. \& Cor, A. (2004). "Nucleus Pulposus Repair with Cultured Autologous Elastic Cartilage Derived Chondrocytes," Cell Mol Biol Lett 9, 363-373.

Gruber, H. E., Fisher, E. C., Jr., Desai, B., Stasky, A. A., Hoelscher, G. \& Hanley, E. N. (1997). "Human Intervertebral Disc Cells from the Annulus: Three-Dimensional Culture in Agarose or Alginate and Responsiveness to TGF-Beta1," Exp Cell Res 235, 13-21.

Gruber, H. E., Ingram, J. A., Davis, D. E. \& Hanley, E. N. (2009). "Increased Cell Senescence is Associated with Decreased Cell Proliferation in Vivo in the Degenerating Human Annulus," Spine J 9, 210-215.

Gruber, H. E., Leslie, K., Norton, H. J., Heiner, D., Patt, J. \& Hanley, E. N. (2006). "Demographic Factors that Influence Human Disc Cell Proliferation in Vitro," Spine J 6, 120-124.

Guilak, F., Ting-Beall, H. P., Baer, A. E., Trickey, W. R., Erickson, G. R. \& Setton, L. A. (1999). "Viscoelastic Properties of Intervertebral Disc Cells. Identification of Two Biomechanically Distinct Cell Populations," Spine (Phila Pa 1976) 24, 2475-2483. 
Hayes, A. J., Isaacs, M. D., Hughes, C., Caterson, B. \& Ralphs, J. R. (2011). "Collagen Fibrillogenesis in the Development of the Annulus Fibrosus of the Intervertebral Disc," Eur Cell Mater 22, 226-241.

Hayes, A. J. \& Ralphs, J. R. (2011). "The Response of Foetal Annulus Fibrosus Cells to Growth Factors: Modulation of Matrix Synthesis by TGF-Beta1 and IGF-1," Histochem Cell Biol 136, 163-175.

Henriksson, H. B. \& Brisby, H. (2012). "Development and Regeneration Potential of the Mammalian Intervertebral Disc," Cells Tissues Organs.

Henriksson, H. B., Svala, E., Skioldebrand, E., Lindahl, A. \& Brisby, H. (2012b). "Support of Concept that Migrating Progenitor Cells from Stem Cell Niches Contribute to Normal Regeneration of the Adult Mammal Intervertebral Disc: A Descriptive Study in the New Zealand White Rabbit," Spine (Phila Pa 1976) 37, 722-732.

Henriksson, H. B., Svanvik, T., Jonsson, M., Hagman, M., Horn, M., Lindahl, A. \& Brisby, H. (2009b). "Transplantation of Human Mesenchymal Stems Cells into Intervertebral Discs in a Xenogeneic Porcine Model," Spine (Phila Pa 1976) 34, 141-148.

Henriksson, H., Hagman, M., Horn, M., Lindahl, A. \& Brisby, H. (2012a). "Investigation of Different Cell Types and gel Carriers for Cell-Based Intervertebral Disc Therapy, in Vitro and in Vivo Studies," J Tissue Eng Regen Med 6, 738-747.

Henriksson, H., Thornemo, M., Karlsson, C., Hagg, O., Junevik, K., Lindahl, A. \& Brisby, H. (2009a). "Identification of Cell Proliferation Zones, Progenitor Cells and a Potential Stem Cell Niche in the Intervertebral Disc Region: A Study in Four Species," Spine (Phila Pa 1976) 34, 2278-2287.

Hiyama, A., Mochida, J., Iwashina, T., Omi, H., Watanabe, T., Serigano, K., Tamura, F. \& Sakai, D. (2008). "Transplantation of Mesenchymal Stem Cells in a Canine Disc
Degeneration Model," J Orthop Res 26, 589 600.

Hohaus, C., Ganey, T. M., Minkus, Y. \& Meisel, H. J. (2008). "Cell Transplantation in Lumbar Spine Disc Degeneration Disease," Eur Spine J 17 Suppl 4, 492-503.

Horner, H. A. \& Urban, J. P. G. (2001). "2001 Volvo Award Winner in Basic Science Studies: Effect of Nutrient Supply on the Viability of Cells from the Nucleus Pulposus of the Intervertebral Disc," Spine (Phila Pa 1976) 26, 2543-2549.

Hunter, C. J., Matyas, J. R. \& Duncan, N. A. (2003). "The Notochordal Cell in the Nucleus Pulposus: A Review in the Context of Tissue Engineering," Tissue Eng 9, 667677.

Illien-Junger, S., Pattappa, G., Peroglio, M., Benneker, L. M., Stoddart, M.J., Sakai, D., Mochida, J., Grad, S. \& Alini, M. (2012). "Homing of Mesenchymal Stem Cells in Induced Degenerative Intervertebral Discs in a Whole Organ Culture System," Spine (Phila Pa 1976) 37, 1865-1873.

Imai, Y., Miyamoto, K., An, H. S., Thonar, E. J., Andersson, G. B. J. \& Masuda, K. (2007). "Recombinant Human Osteogenic Protein1 Upregulates Proteoglycan Metabolism of Human Anulus Fibrosus and Nucleus Pulposus Cells," Spine (Phila Pa 1976) 32, 1303-1309; discussion 1310.

Inkinen, R. I., Lammi, M. J., Lehmonen, S., Puustjarvi, K., Kaapa, E. \& Tammi, M. I. (1998). "Relative Increase of Biglycan and Decorin and Altered Chondroitin Sulfate Epitopes in the Degenerating Human Intervertebral Disc," J Rheumatol 25, 506514.

Iwashina, T., Mochida, J., Sakai, D., Yamamoto, Y., Miyazaki, T., Ando, K. \& Hotta, T. (2006). "Feasibility of Using a Human Nucleus Pulposus Cell Line as a Cell Source in Cell Transplantation Therapy for intervertebral Disc Degeneration," Spine (Phila Pa 1976) 31, 1177-1186.

Jackson, A. R., Huang, C. Y. \& Gu, W. Y. (2011). "Effect of Endplate Calcification 
and Mechanical Deformation on the Distribution of Glucose in Intervertebral Disc: A 3D Finite Element Study," Comput Methods Biomech Biomed Engin 14, 195204.

Jarvinen, L., Badri, L., Wettlaufer, S., Ohtsuka, T., Standiford, T. J., Toews, G. B., Pinsky, D. J., Peters-Golden, M. \& Lama, V. N. (2008). "Lung Resident Mesenchymal Stem Cells Isolated from Human Lung Allografts Inhibit T Cell Proliferation via a Soluble Mediator," J Immunol 181, 43894396.

Ji, J. F., He, B. P., Dheen, S. T. \& Tay, S. S. (2004). "Interactions of Chemokines and Chemokine Receptors Mediate the Migration of Mesenchymal Stem Cells to the Impaired Site in the Brain after Hypoglossal Nerve Injury," Stem Cells 22, 415-427.

Johnstone, B. \& Bayliss, M. T. (1995). "The Large Proteoglycans of the Human Intervertebral Disc. Changes in Their Biosynthesis and Structure with Age, Topography, and Pathology," Spine (Phila Pa 1976) 20, 674-684.

Kalichman, L. \& Hunter, D. J. (2008). "The Genetics of Intervertebral Disc Degeneration," Associated genes. Joint Bone Spine 75, 388-396.

Kang, J. D., Stefanovic-Racic, M., McIntyre, L. A., Georgescu, H. I. \& Evans, C. H. (1997). "Toward a Biochemical Understanding of Human Intervertebral Disc Degeneration and Herniation. Contributions of Nitric Oxide, Interleukins, Prostaglandin E2, and Matrix Metalloproteinases," Spine (Phila Pa 1976) 22, 1065-1073.

Katz, J. N. (2006). "Lumbar Disc Disorders and Low-Back Pain: Socioeconomic Factors and Consequences," J Bone Joint Surg Am 88(Suppl 2), 21-24.

Kim, J. H., Deasy, B. M., Seo, H. Y., Studer, R. K., Vo, N. V., Georgescu, H. I., Sowa, G. A. \& Kang, J. D. (2009a). "Differentiation of Intervertebral Notochordal Cells through Live Automated Cell Imaging System in
Vitro," Spine (Phila Pa 1976) 34, 24862493.

Kim, H. J. \& Im, G. I. (2009). “Combination of Transforming Growth Factor-Beta2 and Bone Morphogenetic Protein 7 Enhances Chondrogenesis from Adipose TissueDerived Mesenchymal Stem Cells," Tissue Eng Part A 15, 1543-1551.

Kim, K. W., Ha, K. Y., Lee, J. S., Nam, S. W., Woo, Y. K., Lim, T. H. \& An, H. S. (2009b). "Notochordal Cells Stimulate Migration of Cartilage End Plate Chondrocytes of the Intervertebral Disc in in Vitro Cell Migration Assays," Spine J 9, 323-329.

Le Maitre, C. L., Baird, P., Freemont, A. J. \& Hoyland, J. A. (2009). "An in Vitro Study Investigating the Survival and Phenotype of Mesenchymal Stem Cells Following Injection into Nucleus Pulposus Tissue," Arthritis Res Ther 11, R20.

Le Maitre, C. L., Freemont, A. J. \& Hoyland, J. A. (2005). "The Role of Interleukin-1 in the Pathogenesis of Human Intervertebral Disc Degeneration," Arthritis Res Ther 7, R732745.

Le Visage, C., Kim, S. W., Tateno, K., Sieber, A. N., Kostuik, J. P. \& Leong, K. W. (2006). "Interaction of Human Mesenchymal Stem Cells with Disc Cells: Changes in Extracellular Matrix Biosynthesis," Spine (Phila Pa 1976) 31, 2036-2042.

Levin, D. A., Hale, J. J. \& Bendo, J. A. (2007). "Adjacent Segment Degeneration Following Spinal Fusion for Degenerative Disc Disease," Bull NYU Hosp Jt Dis 65, 29-36.

Li, H., Liang, C., Tao, Y., Zhou, X., Li, F., Chen, G. \& Chen, Q. X. (2012). “Acidic pH Conditions Mimicking Degenerative Intervertebral Discs Impair the Survival and Biological Behavior of Human AdiposeDerived Mesenchymal Stem Cells," Exp Biol Med (Maywood) 237, 845-852.

Lin, W., Chen, X., Wang, X., Liu, J. \& Gu, X. (2008). "Adult Rat Bone Marrow Stromal Cells Differentiate into Schwann Cell-Like Cells in Vitro," In Vitro Cell Dev Biol Anim 44, 31-40. 
Lin, W. P., Lin, J. H., Chen, X. W., Wu, C. Y., Zhang, L. Q., Huang, Z. D. \& Lai, J. M. (2011). "Interleukin-10 Promoter Polymorphisms Associated with Susceptibility to Lumbar Disc Degeneration in a Chinese Cohort," Genet Mol Res 10, 1719-1727.

Liu, J., Roughley, P. J. \& Mort, J. S. (1991). "Identification of Human Intervertebral Disc Stromelysin and its Involvement in Matrix Degradation," J Orthop Res 9, 568575.

Liu, L. T., Huang, B., Li, C. Q., Zhuang, Y., Wang, J. \& Zhou, Y. (2011a). "Characteristics of Stem Cells Derived from the Degenerated Human Intervertebral Disc Cartilage Endplate," PLoS One 6, e26285.

Liu, Y., Kong, J., Chen, B.- H. \& Hu, Y.- G. (2010). "Combined Expression of CTGF and Tissue Inhibitor of Metalloprotease-1 Promotes Synthesis of Proteoglycan and Collagen Type II in Rhesus Monkey Lumbar Intervertebral Disc Cells in Vitro," Chin Med $J$ (Engl) 123, 2082-2087.

Liu, Y., Li, J.- M. \& Hu, Y.- G. (2011b). "Transplantation of Gene-Modified Nucleus Pulposus Cells Reverses Rabbit Intervertebral Disc Degeneration," Chin Med J (Engl) 124, 2431-2437.

Li, X., Leo, B. M., Beck, G., Balian, G. \& Anderson, G. D. (2004). "Collagen and Proteoglycan Abnormalities in the GDF-5Deficient Mice and Molecular Changes when Treating Disk Cells with Recombinant Growth Factor," Spine (Phila Pa 1976) 29, 2229-2234.

Lyons, G., Eisenstein, S. M. \& Sweet, M. B. E. (1981). "Biochemical Changes in Intervertebral Disc Degeneration," Biochim Biophys Acta 673, 443-453.

Maclean, J. J., Lee, C. R., Alini, M. \& Iatridis, J. C. (2004). "Anabolic and Catabolic mRNA Levels of the Intervertebral Disc Vary with the Magnitude and Frequency of in Vivo Dynamic Compression," J Orthop Res 22, 1193-1200.
MacLean, J. J., Lee, C. R., Alini, M. \& Iatridis, J. C. (2005). "The Effects of Short-Term Load Duration on Anabolic and Catabolic Gene Expression in the Rat Tail Intervertebral Disc," J Orthop Res 23, 11201127.

MacLean, J. J., Lee, C. R., Grad, S., Ito, K., Alini, M. \& Iatridis, J. C. (2003). "Effects of Immobilization and Dynamic Compression on Intervertebral Disc Cell Gene Expression in Vivo," Spine (Phila Pa 1976) 28, 973-981.

Maldonado, B. A. \& Oegema, T. R., Jr. (1992). "Initial Characterization of the Metabolism of Intervertebral Disc Cells Encapsulated in Microspheres," J Orthop Res 10, 677-690.

Masuda, K. (2008). "Biological Repair of the Degenerated Intervertebral Disc by the Injection of Growth Factors," Eur Spine J 17 Suppl 4, 441-451.

Masuda, K., Takegami, K., An, H., Kumano, F., Chiba, K., Andersson, G. B., Schmid, T. \& Thonar, E. (2003). "Recombinant Osteogenic Protein-1 Upregulates Extracellular Matrix Metabolism by Rabbit Annulus Fibrosus and Nucleus Pulposus Cells Cultured in Alginate Beads," J Orthop Res 21, 922-930.

Mauney, J., Olsen, B. R. \& Volloch, V. (2010). "Matrix Remodeling as Stem Cell Recruitment Event: A Novel in Vitro Model for Homing of Human Bone Marrow Stromal Cells to the Site of Injury Shows Crucial Role of Extracellular Collagen Matrix," Matrix Biol 29, 657-663.

McCann, M. R., Tamplin, O. J., Rossant, J. \& Séguin, C. A. (2012). "Tracing NotochordDerived Cells Using a Noto-Cre Mouse: Implications for Intervertebral Disc Development," Disease Models \& Mechanisms 5, 73-82.

Miller, J. A., Schmatz, C. \& Schultz, A. B. (1988). "Lumbar Disc Degeneration: Correlation with Age, Sex, and Spine Level in 600 Autopsy Specimens," Spine (Phila Pa 1976) 13, 173-178. 
Millward-Sadler, S. J., Costello, P. W., Freemont, A. J. \& Hoyland, J. A. (2009). "Regulation of Catabolic Gene Expression in Normal and Degenerate Human Intervertebral Disc Cells: Implications for the Pathogenesis of Intervertebral Disc Degeneration," Arthritis Res Ther 11, R65.

Minogue, B. M., Richardson, S. M., Zeef, L. A. H., Freemont, A. J. \& Hoyland, J. A. (2010). "Characterization of the Human Nucleus Pulposus Cell Phenotype and Evaluation of Novel Marker Gene Expression to Define Adult Stem Cell Differentiation," Arthritis Rheum 62, 3695-3705.

Miyamoto, K., Masuda, K., Kim, J. G., Inoue, N., Akeda, K., Andersson, G. B. \& An, H. S. (2006). "Intradiscal Injections of Osteogenic Protein-1 Restore the Viscoelastic Properties of Degenerated Intervertebral Discs," Spine J 6, 692-703.

Murtaugh, L. C., Chyung, J. H. \& Lassar, A. B. (1999). "Sonic Hedgehog Promotes Somitic Chondrogenesis by Altering the Cellular Response to BMP Signaling," Genes Dev 13, 225-237.

Mwale, F., Roughley, P. \& Antoniou, J. (2004). "Distinction between the Extracellular Matrix of the Nucleus Pulposus and Hyaline Cartilage: A Requisite for Tissue Engineering of Intervertebral Disc," Eur Cell Mater 8, 5863; discussion 63-54.

Nerlich, A. G., Schaaf, R., Walchli, B. \& Boos, N. (2007). "Temporo-Spatial Distribution of Blood Vessels in Human Lumbar Intervertebral Discs," Eur Spine J 16, 547555.

Nishimura, K. \& Mochida, J. (1998). "Percutaneous Reinsertion of the Nucleus Pulposus. An Experimental Study," Spine (Phila Pa 1976) 23, 1531-1538; discussion 1539.

Nomura, T., Mochida, J., Okuma, M., Nishimura, K. \& Sakabe, K. (2001). "Nucleus Pulposus Allograft Retards Intervertebral Disc Degeneration," Clin Orthop Relat Res, 94-101.
O'Halloran, D. M. \& Pandit, A. S. (2007). "Tissue-Engineering Approach to Regenerating the Intervertebral Disc," Tissue Eng 13, 1927-1954.

Okuma, M., Mochida, J., Nishimura, K., Sakabe, K. \& Seiki, K. (2000). "Reinsertion of Stimulated Nucleus Pulposus Cells Retards Intervertebral Disc Degeneration: An in Vitro and in Vivo Experimental Study," J Orthop Res 18, 988-997.

Orozco, L., Soler, R., Morera, C., Alberca, M., Sanchez, A. \& Garcia-Sancho, J. (2011). "Intervertebral Disc Repair by Autologous Mesenchymal Bone Marrow Cells: A Pilot Study," Transplantation 92, 822-828.

Osada, R., Ohshima, H., Ishihara, H., Yudoh, K., Sakai, K., Matsui, H. \& Tsuji, H. (1996). "Autocrine/Paracrine Mechanism of Insulin-Like Growth Factor-1 Secretion, and the Effect of Insulin-Like Growth Factor-1 on Proteoglycan Synthesis in Bovine Intervertebral Discs," J Orthop Res 14, 690-699.

Patel, A. A., Spiker, W. R., Daubs, M., Brodke, D. \& Cannon-Albright, L. A. (2011). "Evidence for an Inherited Predisposition to Lumbar Disc Disease," The Journal of bone and joint surgery American volume 93, 225-229.

Paul, C. P., Zuiderbaan, H. A., Zandieh Doulabi, B., van der Veen, A. J., van de Ven, P. M., Smit, T. H., Helder, M. N., van Royen, B. J. \& Mullender, M. G. (2012). "SimulatedPhysiological Loading Conditions Preserve Biological and Mechanical Properties of Caprine Lumbar Intervertebral Discs in Ex Vivo Culture," PLoS One 7, e33147.

Pfirrmann, C. W. A., Metzdorf, A., Zanetti, M., Hodler, J. \& Boos, N. (2001). "Magnetic Resonance Classification of Lumbar Intervertebral Disc Degeneration," Spine (Phila Pa 1976) 26, 1873-1878.

Pittenger, M. F., Mackay, A. M., Beck, S. C., Jaiswal, R. K., Douglas, R., Mosca, J. D., Moorman, M. A., Simonetti, D. W., Craig, S. \& Marshak, D. R. (1999). "Multilineage Potential of Adult Human Mesenchymal Stem Cells," Science 284, 143-147. 
Ponte, A. L., Marais, E., Gallay, N., Langonne, A., Delorme, B., Herault, O., Charbord, P. \& Domenech, J. (2007). "The in Vitro Migration Capacity of Human Bone Marrow Mesenchymal Stem Cells: Comparison of Chemokine and Growth Factor Chemotactic Activities," Stem Cells 25, 1737-1745.

Power, K. A., Grad, S., Rutges, J. P., Creemers, L. B., van Rijen, M. H., O'Gaora, P., Wall, J. G., Alini, M., Pandit, A. \& Gallagher, W. M. (2011). "Identification of Cell Surface-Specific Markers to Target Human Nucleus Pulposus Cells: Expression of Carbonic Anhydrase XII Varies with Age and Degeneration," Arthritis Rheum 63, 3876-3886.

Pratsinis, H., Constantinou, V., Pavlakis, K., Sapkas, G. \& Kletsas, D. (2012). "Exogenous and Autocrine Growth Factors Stimulate Human Intervertebral Disc Cell Proliferation via the ERK and Akt Pathways," J Orthop Res 30, 958-964.

Puetzer, J. L., Petitte, J. N. \& Loboa, E. G. (2010). "Comparative Review of Growth Factors for Induction of Three-Dimensional in Vitro Chondrogenesis in Human Mesenchymal Stem Cells Isolated from Bone Marrow and Adipose Tissue," Tissue Eng Part B Rev 16, 435-444.

Raj, P. P. ( 2008). "Intervertebral Disc: Anatomy-Physiology-Pathophysiology-

Treatment," Pain practice : the official journal of World Institute of Pain 8, 18-44.

Rajpurohit, R., Risbud, M. V., Ducheyne, P., Vresilovic, E. J. \& Shapiro, I. M. (2002). "Phenotypic Characteristics of the Nucleus Pulposus: Expression of Hypoxia Inducing Factor-1, Glucose Transporter-1 and MMP2," Cell Tissue Res 308, 401-407.

Richardson, S. M., Hoyland, J. A., Mobasheri, R., Csaki, C., Shakibaei, M. \& Mobasheri, A. (2010). "Mesenchymal Stem Cells in Regenerative Medicine: Opportunities and Challenges for Articular Cartilage and Intervertebral Disc Tissue Engineering," J Cell Physiol 222, 23-32.

Richardson, S. M., Mobasheri, A., Freemont, A. J. \& Hoyland, J. A. (2007). "Intervertebral
Disc Biology, Degeneration and Novel Tissue Engineering and Regenerative Medicine Therapies," Histol Histopathol 22, 1033-1041.

Richardson, S. M., Walker, R. V., Parker, S., Rhodes, N. P., Hunt, J. A., Freemont, A. J. \& Hoyland, J. A. (2006). "Intervertebral Disc Cell-Mediated Mesenchymal Stem Cell Differentiation," Stem Cells 24, 707-716.

Ries, C., Egea, V., Karow, M., Kolb, H., Jochum, M. \& Neth, P. (2007). "MMP-2, MT1-MMP, and TIMP-2 are Essential for the Invasive Capacity of Human Mesenchymal Stem Cells: Differential Regulation by Inflammatory Cytokines," Blood 109, 4055-4063.

Risbud, M. V., Albert, T. J., Guttapalli, A., Vresilovic, E. J., Hillibrand, A. S., Vaccaro, A. R. \& Shapiro, I. M. (2004). "Differentiation of Mesenchymal Stem Cells towards a Nucleus Pulposus-Like Phenotype in Vitro: Implications for Cell-Based Transplantation Therapy," Spine (Phila Pa 1976) 29, 2627-2632.

Risbud, M. V., Guttapalli, A., Stokes, D. G., Hawkins, D., Danielson, K. G., Schaer, T. P., Albert, T. J. \& Shapiro, I. M. (2006). "Nucleus Pulposus Cells Express HIF-1 Alpha under Normoxic Culture Conditions: A Metabolic Adaptation to the Intervertebral Disc Microenvironment," J Cell Biochem 98, 152-159.

Risbud, M. V., Guttapalli, A., Tsai, T. T., Lee, J. Y., Danielson, K. G., Vaccaro, A. R., Albert, T. J., Gazit, Z., Gazit, D. \& Shapiro, I. M. (2007). "Evidence for Skeletal Progenitor Cells in the Degenerate Human Intervertebral Disc," Spine (Phila Pa 1976) 32, 2537-2544.

Risbud, M. V. \& Shapiro, I. M. (2011). "Notochordal Cells in the Adult Intervertebral Disc: New Perspective on an Old Question," Crit Rev Eukaryot Gene Expr 21, 29-41.

Roberts, S., Eisenstein, S. M., Menage, J., Evans, E. H. \& Ashton, I. K. (1995). "Mechanoreceptors in Intervertebral Discs. Morphology, Distribution, and 
Neuropeptides," Spine (Phila Pa 1976) 20, 2645-2651.

Roberts, S., Evans, E. H., Kletsas, D., Jaffray, D. C. \& Eisenstein, S. M. (2006). "Senescence in Human Intervertebral Discs," Eur Spine J 15 Suppl 3, S312-316.

Sakai, D. (2008). "Future Perspectives of Cell-Based Therapy for Intervertebral Disc Disease," Eur Spine J 17 Suppl 4, 452-458.

Sakai, D., Mochida, J., Iwashina, T., Hiyama, A., Omi, H., Imai, M., Nakai, T., Ando, K. \& Hotta, T. (2006). "Regenerative Effects of Transplanting Mesenchymal Stem Cells Embedded in Atelocollagen to the Degenerated Intervertebral Disc," Biomaterials 27, 335-345.

Sakai, D., Mochida, J., Iwashina, T., Watanabe, T., Nakai, T., Ando, K. \& Hotta, T. (2005). "Differentiation of Mesenchymal Stem Cells Transplanted to a Rabbit Degenerative Disc Model: Potential and Limitations for Stem Cell Therapy in Disc Regeneration," Spine (Phila Pa 1976) 30, 2379-2387.

Sakai, D., Mochida, J., Yamamoto, Y., Nomura, T., Okuma, M., Nishimura, K., Nakai, T., Ando, K. \& Hotta, T. (2003). "Transplantation of Mesenchymal Stem Cells Embedded in Atelocollagen Gel to the Intervertebral Disc: A Potential Therapeutic Model for Disc Degeneration," Biomaterials 24, 3531-3541.

Satija, N. K., Gurudutta, G. U., Sharma, S., Afrin, F., Gupta, P., Verma, Y. K., Singh, V. K. \& Tripathi, R. P. (2007). "Mesenchymal Stem Cells: Molecular Targets for Tissue Engineering," Stem Cells Dev 16, 7-23.

Schmitt, B., Ringe, J., Haupl, T., Notter, M., Manz, R., Burmester, G. R., Sittinger, M. \& Kaps, C. (2003). "BMP2 Initiates Chondrogenic Lineage Development of Adult Human Mesenchymal Stem Cells in High-Density Culture," Differentiation 71, 567-577.

Sedowofia, K. A., Tomlinson, I. W., Weiss, J. B., Hilton, R. C. \& Jayson, M. I. (1982). "Collagenolytic Enzyme Systems in Human
Intervertebral Disc: Their Control, Mechanism, and Their Possible Role in the Initiation of Biomechanical Failure," Spine (Phila Pa 1976) 7, 213-222.

See, E. Y., Toh, S. L. \& Goh, J. C. (2011). "Effects of Radial Compression on a Novel Simulated Intervertebral Disc-Like Assembly Using Bone Marrow-Derived Mesenchymal Stem Cell Cell-Sheets for Annulus Fibrosus Regeneration," Spine (Phila Pa 1976) 36, 1744-1751.

See, E. Y., Toh, S. L. \& Goh, J. C. (2012). "Simulated Intervertebral Disc-Like Assembly Using Bone Marrow-Derived Mesenchymal Stem Cell Sheets and Silk Scaffolds for Annulus Fibrosus Regeneration," J Tissue Eng Regen Med 6, 528-535.

Shang, X. P., Sun, X. C., Wang, Y. X. \& Ju, B. B. (2012). "Association of BCL-2 Polymorphism with the Presence and Severity of Lumbar Disc Degeneration in the Chinese Han Population," Clin Lab 58, 261-266.

Sheikh, H., Zakharian, K., De La Torre, R. P., Facek, C., Vasquez, A., Chaudhry, G. R., Svinarich, D. \& Perez-Cruet, M. J. (2009). "In Vivo Intervertebral Disc Regeneration Using Stem Cell-Derived Chondroprogenitors," J Neurosurg Spine 10, 265-272.

Shen, B., Bhargav, D., Wei, A., Williams, L. A., Tao, H., Ma, D. D. \& Diwan, A. D. (2009a). "BMP-13 Emerges as a Potential Inhibitor of Bone Formation," Int J Biol Sci 5, 192200.

Shen, B., Wei, A., Tao, H., Diwan, A. D. \& Ma, D. D. (2009b). "BMP-2 Enhances TGFBeta3-Mediated Chondrogenic Differentiation of Human Bone Marrow Multipotent Mesenchymal Stromal Cells in Alginate Bead Culture," Tissue Eng Part A 15, 1311-1320.

Shi, S. \& Gronthos, S. (2003). "Perivascular Niche of Postnatal Mesenchymal Stem Cells in Human Bone Marrow and Dental Pulp," J Bone Miner Res 18, 696-704. 
Sivakamasundari, V. \& Lufkin, T. (2012). "Bridging the Gap: Understanding Embryonic Intervertebral Disc Development," Cell Dev Biol 1.

Smits, P. \& Lefebvre, V. R. (2003). 'Sox5 and Sox6 are Required for Notochord Extracellular Matrix Sheath Formation, Notochordal Cell Survival and Development of the Nucleus Pulposus of Intervertebral Discs,' Development 130.

Solovieva, S., Noponen, N., Mannikko, M., Leino-Arjas, P., Luoma, K., Raininko, R., AlaKokko, L. \& Riihimaki, H. (2007). "Association between the Aggrecan Gene Variable Number of Tandem Repeats Polymorphism and Intervertebral Disc Degeneration," Spine (Phila Pa 1976) 32, 1700-1705.

Steck, E., Bertram, H., Abel, R., Chen, B., Winter, A. \& Richter, W. (2005). "Induction of Intervertebral Disc-Like Cells from Adult Mesenchymal Stem Cells," Stem Cells 23, 403-411.

Sternlicht, M. D. \& Werb, Z. (2001). "How Matrix Metalloproteinases Regulate Cell Behavior," Annu Rev Cell Dev Biol 17, 463516.

Stevens, J. W., Kurriger, G. L., Carter, A. S. \& Maynard, J. A. (2000). "CD44 Expression in the Developing and Growing Rat Intervertebral Disc," Dev Dyn 219, 381-390.

Strassburg, S., Hodson, N. W., Hill, P. I., Richardson, S. M. \& Hoyland, J. A. (2012). "Bi-Directional Exchange of Membrane Components Occurs during Co-Culture of Mesenchymal Stem Cells and Nucleus Pulposus Cells," PLoS One 7, e33739.

Sun, Z. M., Ling, M., Huo, Y., Chang, Y., Li, Y., Qin, H., Yang, G. \& Lucas, R. (2011). "Caspase 9 Gene Polymorphism and Susceptibility to Lumbar Disc Disease in the Han Population in Northern China," Connect Tissue Res 52, 198-202.

Sun, Z. M., Miao, L., Zhang, Y. G. \& Ming, L. (2009). "Association between the -1562 $\mathrm{C} / \mathrm{T}$ Polymorphism of Matrix Metalloproteinase-9 Gene and Lumbar Disc
Disease in the Young Adult Population in North China," Connect Tissue Res 50, 181185.

Thompson, J. P., Oegema, T. R., Jr. \& Bradford, D. S. (1991). "Stimulation of Mature Canine Intervertebral Disc by Growth Factors," Spine (Phila Pa 1976) 16, 253-260.

Tim Yoon, S., Su Kim, K., Li, J., Soo Park, J., Akamaru, T., Elmer, W. A. \& Hutton, W. C. (2003). "The Effect of Bone Morphogenetic Protein-2 on Rat Intervertebral Disc Cells in Vitro," Spine (Phila Pa 1976) 28, 17731780 .

Tolar, J., Nauta, A. J., Osborn, M. J., Panoskaltsis Mortari, A., McElmurry, R. T., Bell, S., Xia, L., Zhou, N., Riddle, M., Schroeder, T. M. et al. (2007). "Sarcoma Derived from Cultured Mesenchymal Stem Cells," Stem Cells 25, 371-379.

Trout, J. J., Buckwalter, J. A., Moore, K. C. \& Landas, S. K. (1982). "Ultrastructure of the Human Intervertebral Disc. I. Changes in Notochordal Cells with Age," Tissue Cell 14, 359-369.

Uchio, Y., Ochi, M., Matsusaki, M., Kurioka, H. \& Katsube, K. (2000). "Human Chondrocyte Proliferation and Matrix Synthesis Cultured in Atelocollagen Gel," J Biomed Mater Res 50, 138-143.

Videman, T., Saarela, J., Kaprio, J., Nakki, A., Levalahti, E., Gill, K., Peltonen, L. \& Battie, M. C. (2009). "Associations of 25 Structural, Degradative, and Inflammatory Candidate Genes with Lumbar Disc Desiccation, Bulging, and Height Narrowing," Arthritis Rheum 60, 470-481.

Walker, B. F. (2000). "The Prevalence of Low Back Pain: A Systematic Review of the Literature from 1966 to 1998," J Spinal Disord 13, 205-217.

Wallach, C. J., Sobajima, S., Watanabe, Y., Kim, J. S., Georgescu, H. I., Robbins, P., Gilbertson, L. G. \& Kang, J. D. (2003). “Gene Transfer of the Catabolic Inhibitor TIMP-1 Increases Measured Proteoglycans in Cells from Degenerated Human Intervertebral 
Discs," Spine (Phila Pa 1976) 28, 23312337.

Walmsley, R. (1953). "The Development and Growth of the Intervertebral Disc," Edinb Med J 60, 341-364.

Walsh, A. J. L., Bradford, D. S. \& Lotz, J. C. (2004). "In Vivo Growth Factor Treatment of Degenerated Intervertebral Discs," Spine (Phila Pa 1976) 29, 156-163.

Walsh, A. J. L. \& Lotz, J. C. (2004). "Biological Response of the Intervertebral Disc to Dynamic Loading," J Biomech 37, 329-337.

Wang, J., Markova, D., Anderson, D. G., Zheng, Z., Shapiro, I. M. \& Risbud, M. V. (2011). "TNF-Alpha and IL-1beta Promote a Disintegrin-Like and Metalloprotease With Thrombospondin Type I Motif-5Mediated Aggrecan Degradation through Syndecan-4 in Intervertebral Disc," J Biol Chem 286, 39738-39749.

Wang, Q. W., Chen, Z. L. \& Piao, Y. J. (2005). "Mesenchymal Stem Cells Differentiate into Tenocytes by Bone Morphogenetic Protein (BMP) 12 Gene Transfer," J Biosci Bioeng $100,418-422$.

Wash, E. (2012). "Washington Center for Pain Management Begins Enrollment in United States Stem Cell Therapy Study in Subjects With Chronic Back Pain," (PRNewswire).

Watanabe, T., Sakai, D., Yamamoto, Y., Iwashina, T., Serigano, K., Tamura, F. \& Mochida, J. (2010). "Human Nucleus Pulposus Cells Significantly Enhanced Biological Properties in a Coculture System with Direct Cell-To-Cell Contact with Autologous Mesenchymal Stem Cells," J Orthop Res 28, 623-630.

Wei, A., Chung, S. A., Tao, H., Brisby, H., Lin, Z., Shen, B., Ma, D. D. \& Diwan, A. D. (2009a). "Differentiation of Rodent Bone Marrow Mesenchymal Stem Cells into Intervertebral Disc-Like Cells Following Coculture with Rat Disc Tissue," Tissue Eng Part A 15, 2581-2595.
Wei, A., Williams, L. A., Bhargav, D., Shen, B., Kishen, T., Duffy, N. \& Diwan, A. D. (2009b). "BMP13 Prevents the Effects of Annular Injury in an Ovine Model," Int J Biol Sci 5, 388-396.

Wilke, H. J., Neef, P., Caimi, M., Hoogland, T. \& Claes, L. E. (1999). "New in Vivo Measurements of Pressures in the Intervertebral Disc in Daily Life," Spine (Phila Pa 1976) 24, 755-762.

Wuertz, K., Godburn, K., MacLean, J. J., Barbir, A., Donnelly, J. S., Roughley, P. J., Alini, M. \& Iatridis, J. C. (2009). "In Vivo Remodeling of Intervertebral Discs in Response to Short- and Long-Term Dynamic Compression," J Orthop Res 27, 1235-1242.

Yamamoto, Y., Mochida, J., Sakai, D., Nakai, T., Nishimura, K., Kawada, H. \& Hotta, T. (2004). "Upregulation of the Viability of Nucleus Pulposus Cells by Bone MarrowDerived Stromal Cells: Significance of Direct Cell-To-Cell Contact in Coculture System," Spine (Phila Pa 1976) 29, 15081514.

Zara, J. N., Siu, R. K., Zhang, X., Shen, J., Ngo, R., Lee, M., Li, W., Chiang, M., Chung, J., Kwak, J. et al. (2011). "High Doses of Bone Morphogenetic Protein 2 Induce Structurally Abnormal Bone and Inflammation in Vivo," Tissue Eng Part A $17,1389-1399$.

Zhang, Y., Chee, A., Thonar, E. J. \& An, H. S. (2011). "Intervertebral Disk Repair by Protein, Gene, or Cell Injection: A Framework for Rehabilitation-Focused Biologics in the Spine," $P m$ R 3, S88-94. 